\title{
Sun Irradiance Trappers for Solar PV Module to Operate On Maximum Power: An Experimental Study
}

\section{Ankur Kumar Gupta ${ }^{a^{*}}$, Shushma Kakkar ${ }^{b}$, Rachna Chaudhary ${ }^{c}$, Pankaj Kumar Gupta $^{d}$, Rupendra Kumar Pachaurie}

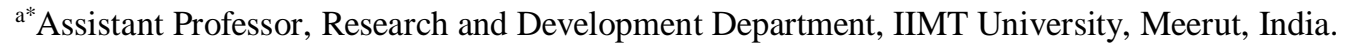 \\ E-mail: ankursca@iimtindia.net \\ ${ }^{\mathrm{b}}$ Research Scholar, MME IIT (ISM) DHANBAD, India. E-mail: sushmakakkar75@gmail.com \\ ${ }^{\mathrm{c}}$ Associate Professor, School of Computer Science and Application, IIMT University, Meerut, India. \\ E-mail: rachnacs1088@gmail.com \\ ${ }^{\mathrm{d} A s s o c i a t e}$ Professor, School of Computer Science and Application, IIMT University, Meerut, India. \\ E-mail: drpkg03@gmail.com \\ ${ }^{\mathrm{e}}$ Electrical and Electronics Department, School of Engineering, University of Petroleum and Energy Studies, \\ Dehradun, India. E-mail: rpachauri@ddn.upes.ac.in
}

Article History: Received: 11 January 2021; Accepted: 27 February 2021; Published online: 5 April 2021

\begin{abstract}
In this paper, an experimental investigation carries out on poly-crystalline photovoltaic (PV) system for performance enhancement with the help of a thin acrylic sheet (thickness- $2 \mathrm{~mm}$ ). There are three types of systems used under this experimental setup as (i) PV module under normal conditions/ without sheet (ii) PV module under the triangular shape of the transparent sheet (iii) PV module under rectangular shape transparent sheet. The performance analysis of all three systems has been monitored in terms of open-circuit voltage, short circuit current, power, efficiency. Simultaneously, a statistical measurement approach of sun irradiation with constant temperature is carried out during the single day experimental study. The performance of the (Triangular shaped transparent sheet) TSTS configuration found superior which provide 22.064 Watt power at 12 am, whereas (Rectangular shaped transparent sheet) RSTS configuration provide $20.4 \mathrm{~W}$ at the same time. The TSTS configuration provides 1.12A short circuit current at $12 \mathrm{am}$, whereas RSTS configuration provides $1.02 \mathrm{~A}$ short circuit current at the same time. The TSTS configuration provides $8.92 \%$ better value. The TSTS configuration provides $20 \mathrm{~V}$ open-circuit voltage at $12 \mathrm{am}$, whereas RSTS configuration provides $19.8 \mathrm{~V}$ open-circuit voltage at the same time. The TSTS configuration provides $1 \%$ higher value. So that the TSTS configuration provides the maximum output of the solar PV panel.
\end{abstract}

Keywords: Trapping methods, photovoltaic system, poly-crystalline, transparent acrylic sheet, power enhancement.

\section{Introduction}

The global interest is increasing day-by-day towards solar photovoltaic (PV) sector, because of the renewable energy (RE) industry promising choice. The intelligent grid offers load management and shipments of storage devices to maximize solar PV efficiency as a grid. As per an available report from last decades, it is estimated that the world PV technology sector has expanded by an average of $30 \%$ percent annually [1]. It is well known that the conversion.

The efficiency of PV system technology is still relatively low, so that energy is extracted as much as possible in a usable PV power system through some experimental methodologies.

There are many problems with PV electricity generation systems. Because of numerous technological and environmental factors, the short circuit (SC) current of the PV cell varies. Although PV cells and modules' development will mitigate technical reasons, the environmental reasons can't be avoided [2]. The key atmosphere explanation for irregular SC current is that the PV array is partly shaded. The panels are dirty and dusty, shadows on the tablet due to the passing clouds, surrounding trees and constructions etc. The authors of [3-4] addressed the increment in PV cells' electric efficiency through concentration and cooling techniques. The cooling processes of two PV cells were addressed first through a heat pipe system for direct water cooling and cooling. If the PV cell temperature increases, then the PV cell terminal voltage decreases. The authors discussed the latest optimization for high-efficiency in thin-film silicon PV cells [5]. The basic PV cell should slightly restrict the short-circuit current ( $\mathrm{I}_{\mathrm{SC}}$ ) for performance enhancement. In [6-7] the authors showed that solar panels' performance using solar concentration had been enhanced with simple flat mirrors, cooling technology and the efficiency improvements of both techniques being compared. In [8], the authors used reflectors and a solar 
tracker system to boost the solar photovoltaic system's efficiency for full solar photovoltaic output. Comparative research was performed on a solar PV panel with diffused reflector and solar power tracker. Therefore, researchers still challenge to boost solar PV systems output to meet maximum solar irradiation and concentrate first and foremost on new ways of achieving maximum solar irradiation [9]. In [10], the authors addressed and presented a brief overview of solar PV system efficiency changes using the flat hybrid PV/ thermal solar system. The authors addressed improving solar PV system performance with flat-screen reflectors. Solar PV system performance with reflectors depends mainly on three parameters: tilt-angle, panel length and reflector reflectivity [11-13].

This paper's innovation aims to improve the solar PV system's efficiency, inspired by the above-mentioned literary analysis. There has been a hardware framework for enhancing solar PV system performance by absorbing sun radiation trapping methodology [14-18].

\subsection{Novelty of Work}

The conversion efficiency of the PV module from solar irradiation into electricity is observed very low. With the motivation of the above literature review, the solar irradiation trapping methods are identified for the extensive investigations as,

- In the current scenario, the plane surface glass has been used to protect the solar cell.

- To increase the solar panel's efficiency, the different shaped transparent sheet is mounted on the solar panel.

- The main aim of this study is to harvest maximum power from a solar PV module using the triangular and rectangular shape of the transparent acrylic sheet (thickness: $2 \mathrm{~mm}$ )

- During the one day investigation, the performance comparison is carried out in terms of open-circuit voltage, short circuit current, and efficiency for the considered systems.

The assessment of PV module temperature and solar irradiation levels are done during the experimental investigation.

\section{Description of the Experimental System}

The present experimental study is performed in March 2020 at Dehradun, Uttarakhand. The weather is partial cloudy and geographical coordinates are $30.3165^{\circ} \mathrm{N}$ and $78.0322^{\circ} \mathrm{E}$ during the experimentation. The experimental setup is shown in figure 1 . The three poly-crystalline photovoltaic panels of the same rating have been used for this purpose. The rating of the solar panel is provided in table no 1. In this setup, the hard plastic sheet of $2 \mathrm{~mm}$ has been used. The different shapes of sheet mounted on the top of the solar panel. The solar panel fitted on 45 degrees. The panels are adjusted according to the azimuth angle and available maximum window area. The three solar panels are configured as one panel with a triangular shaped sheet and the second panel with a rectangular shape of a transparent sheet, and the third panel is without any sheet as shown in figure 1 . The irradiance meter, voltmeter, current meter are used for measurement purpose.

Table 1. Datasheet of considered Polycrystalline PV module: 20W (Manuf.: Spark Solar)

\begin{tabular}{ll}
\hline PV performance parameters & Values \\
\hline Rated maximum power (Pmax) & $20 \mathrm{~W}$ \\
Voltage at Pmax & $18.25 \mathrm{~V}$ \\
Current at Pmax & $1.10 \mathrm{~A}$ \\
Open-circuit voltage (Voc) & $21.96 \mathrm{~V}$ \\
Short circuit current (Isc) & $1.17 \mathrm{~A}$ \\
Cell technology & Poly-Si \\
Nominal operating cell temperature (NOCT) & $47^{\circ} \mathrm{C}$ \\
Solar irradiance & $1000 \mathrm{~W} / \mathrm{m}^{2}$ \\
\hline
\end{tabular}




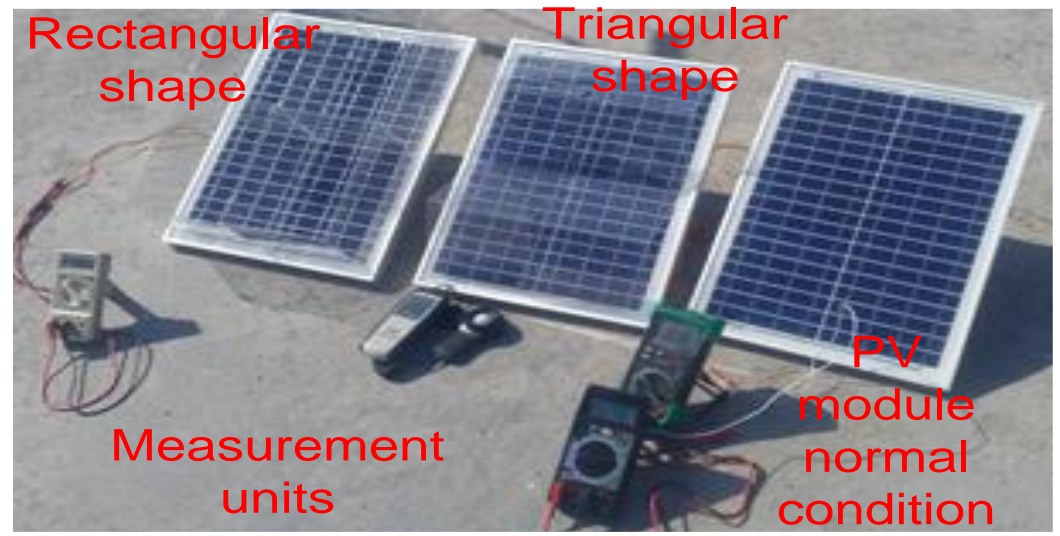

(a) Front view

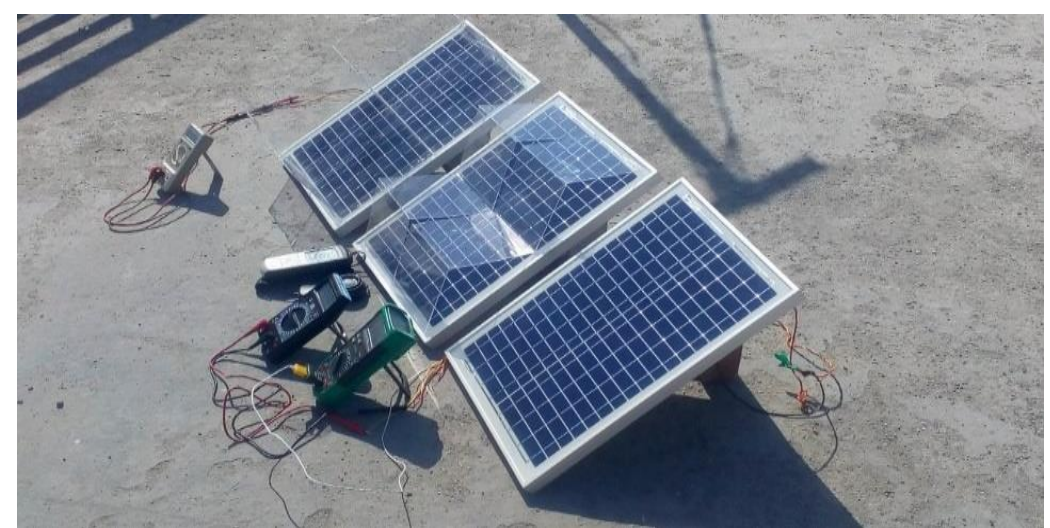

(b) Side view

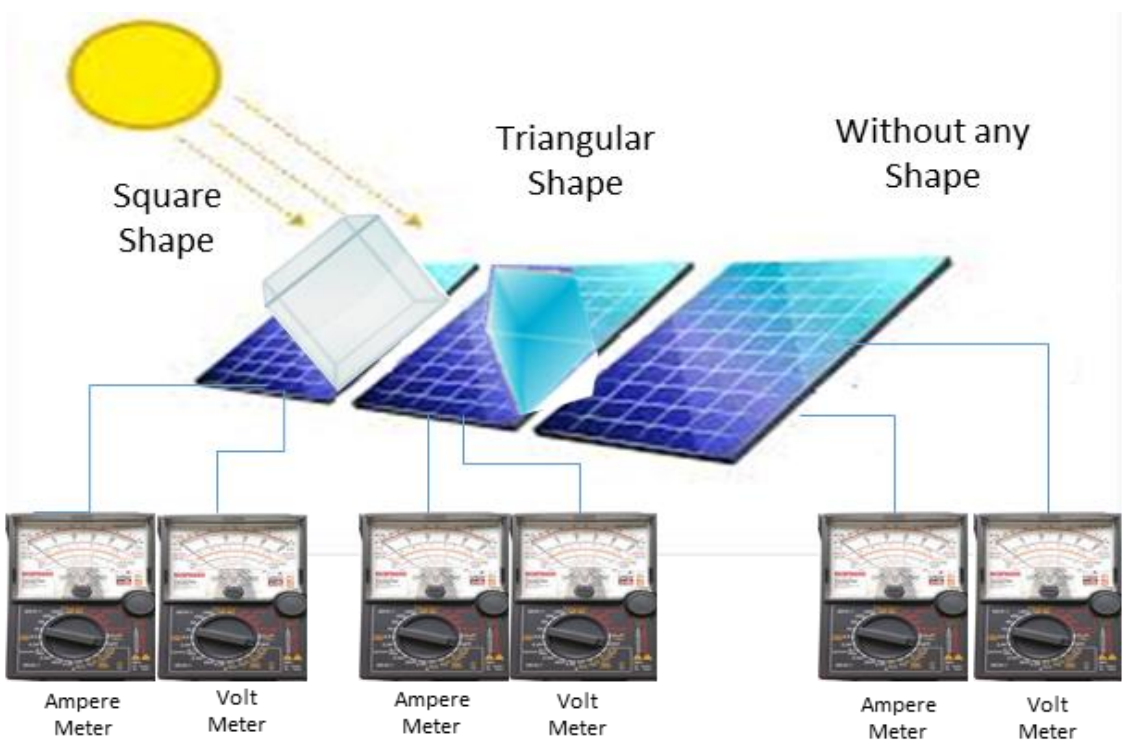

(c) Experimental Setup

Figure 1. Experimental setup for performance investigation

The experimental setup is shown in Fig. 1(c). All the panel are connected with Amp meter and voltmeter, as shown in Fig. 1(c).

\section{Results and Discussion}

For the measurement and comparison, all the panel has been exposed under sky from 8 am to $4 \mathrm{pm}$. The power curve of solar panel with TSTS (Triangular shaped transparent sheet) is higher than the solar panel with RSTS (rectangular shaped transparent sheet) and normal panel. All the power curve are shown in figure 2. However, the panel with TSTS and RSTS provide the same value at $9 \mathrm{am}$, and 11:45 am. But the overall power 
Sun Irradiance Trappers for Solar PV Module to Operate On Maximum Power: An Experimental Study

is high only for TSTS condition. The other performance curve for short circuit current and open-circuit voltage is shown in figure 3 and figure 4.

Table 2. Voltages of Different configuration w.r.t time

\begin{tabular}{|c|c|c|c|}
\hline & Triangular & Rectangular & Normal \\
\hline Time & Volt & Volt & Volt \\
\hline 08:00 & 17.5 & 17.3 & 17.4 \\
\hline 08:15 & 18.1 & 17.9 & 17.9 \\
\hline 08:30 & 18.6 & 18.4 & 18.6 \\
\hline 08:45 & 19.6 & 19.4 & 19.4 \\
\hline 09:00 & 20.6 & 20.4 & 20.1 \\
\hline 09:15 & 20.6 & 20.4 & 20.2 \\
\hline 09:30 & 20.5 & 20.3 & 20.2 \\
\hline 09:45 & 20.3 & 20.1 & 20.2 \\
\hline 10:00 & 20.3 & 20.1 & 20 \\
\hline 10:15 & 20.3 & 20.1 & 19.9 \\
\hline $10: 30$ & 20.2 & 20 & 19.7 \\
\hline 10:45 & 20 & 19.8 & 19.6 \\
\hline 11:00 & 20.1 & 19.9 & 19.78 \\
\hline $11: 15$ & 20.2 & 20 & 19.65 \\
\hline $11: 30$ & 20.1 & 19.9 & 19.7 \\
\hline 11:45 & 20 & 19.8 & 19.73 \\
\hline 12:00 & 20 & 19.8 & 19.7 \\
\hline $12: 15$ & 20 & 19.8 & 19.6 \\
\hline $12: 30$ & 19.9 & 19.7 & 19.5 \\
\hline $12: 45$ & 20 & 19.8 & 19.8 \\
\hline 01:00 & 19.9 & 19.7 & 19.7 \\
\hline 01:15 & 20 & 19.8 & 19.6 \\
\hline 01:30 & 20.1 & 19.9 & 19.8 \\
\hline 01:45 & 20.2 & 20 & 19.7 \\
\hline 02:00 & 20.1 & 19.9 & 19.7 \\
\hline 02:15 & 20.2 & 20 & 19.8 \\
\hline 02:30 & 20.1 & 19.9 & 19.73 \\
\hline 02:45 & 20.3 & 20.1 & 19.86 \\
\hline 03:00 & 20.3 & 20.1 & 19.82 \\
\hline 03:15 & 20.3 & 20.1 & 19.84 \\
\hline 03:30 & 20.1 & 19.9 & 19.85 \\
\hline 03:45 & 19.8 & 19.6 & 19.84 \\
\hline 04:00 & 19.5 & 19.3 & 19.78 \\
\hline
\end{tabular}

Table 2. shows the value of Open-circuit Voltage of different configuration concerning time.

\subsection{Performance Investigation of a Solar PV Module under Normal Conditions}

The performance of solar panel (Without any sheet) is lower than the solar panel performance with TSTS and RSTS. It is shown clearly from the figure 2, 3, 4 that the associated power short current and open-circuit voltage is lower in comparison of other arrangements. 
Ankur Kumar Gupta ${ }^{\mathrm{a}^{*}}$, Shushma Kakkar ${ }^{\mathrm{b}}$, Rachna Chaudhary ${ }^{\mathrm{c}}$, Pankaj Kumar Gupta ${ }^{\mathrm{d}}$, Rupendra Kumar Pachauri ${ }^{\mathrm{e}}$

Table 3. The output power of Different configuration w.r.t Time

\begin{tabular}{llll}
\hline Time & Triangular & Rectangular & Normal \\
\hline & (Watt) & (Watt) & (Watt) \\
$08: 00$ & 6.264 & 4.9 & 4.152 \\
$08: 15$ & 8.592 & 7.964 & 6.444 \\
$08: 30$ & 10.23 & 8.928 & 7.912 \\
$08: 45$ & 12.222 & 11.564 & 9.894 \\
$09: 00$ & 15.276 & 15.244 & 13.056 \\
$09: 15$ & 16.766 & 15.45 & 14.484 \\
$09: 30$ & 18.382 & 15.785 & 16.037 \\
$09: 45$ & 19.796 & 16.24 & 17.286 \\
$10: 00$ & 20.6 & 16.443 & 18.291 \\
$10: 15$ & 21.094 & 17.052 & 18.894 \\
$10: 30$ & 21.276 & 17.776 & 19.2 \\
$10: 45$ & 21.168 & 18 & 19.008 \\
$11: 00$ & 21.9558 & 18.492 & 19.701 \\
$11: 15$ & 21.8115 & 18.584 & 19.8 \\
$11: 30$ & 22.261 & 20.301 & 20.099 \\
$11: 45$ & 21.9003 & 21.6 & 19.602 \\
$12: 00$ & 22.064 & 20.4 & 19.8 \\
$12: 15$ & 21.168 & 18.2 & 19.008 \\
$12: 30$ & 21.16 & 18.1 & 18.124 \\
$12: 45$ & 20.196 & 18 & 17.82 \\
$01: 00$ & 19.7 & 17.71 & 17.336 \\
$01: 15$ & 19.66 & 17.4 & 15.84 \\
$01: 30$ & 19.11 & 16.4 & 14.726 \\
$01: 45$ & 18.56 & 15.342 & 13 \\
$02: 00$ & 17.22 & 14.88 & 11.343 \\
$02: 15$ & 16.55 & 12.742 & 10.2 \\
$02: 30$ & 15.11 & 12.11 & 9.22 \\
$02: 45$ & 14.11 & 11.165 & 8.33 \\
$03: 00$ & 13 & 10.556 & 7.32 \\
$03: 15$ & 11 & 9.11 & 5.89 \\
$03: 30$ & 8.84 & 8.11 & 5.373 \\
$03: 45$ & 7.5392 & 7 & 5.096 \\
$04: 00$ & 7.1208 & 6 & 4.632 \\
\hline & & & \\
& & \\
0 & & \\
0
\end{tabular}

Table 3. shows the value of the output power of different configuration concerning time.

\subsection{Performance Investigation of a Solar PV Module under the Triangular Shape of a Transparent Sheet}

The performance of solar panel with TSTS configuration is higher than other configuration under the same conditions. The power, short circuit current and open-circuit voltage are higher in comparison with other configurations. 
Sun Irradiance Trappers for Solar PV Module to Operate On Maximum Power: An Experimental Study

Table 4. Output Current of Different configuration w.r.t Time

\begin{tabular}{llll}
\hline & Triangular & Rectangular & Normal \\
\hline Time & I & I & I \\
$08: 00$ & 0.36 & 0.28 & 0.24 \\
$08: 15$ & 0.48 & 0.44 & 0.36 \\
$08: 30$ & 0.55 & 0.48 & 0.43 \\
$08: 45$ & 0.63 & 0.59 & 0.51 \\
$09: 00$ & 0.76 & 0.74 & 0.64 \\
$09: 15$ & 0.83 & 0.75 & 0.71 \\
$09: 30$ & 0.91 & 0.77 & 0.79 \\
$09: 45$ & 0.98 & 0.8 & 0.86 \\
$10: 00$ & 1.03 & 0.81 & 0.91 \\
$10: 15$ & 1.06 & 0.84 & 0.94 \\
$10: 30$ & 1.08 & 0.88 & 0.96 \\
$10: 45$ & 1.08 & 0.9 & 0.96 \\
$11: 00$ & 1.11 & 0.92 & 0.99 \\
$11: 15$ & 1.11 & 0.92 & 0.99 \\
$11: 30$ & 1.13 & 1.01 & 1.01 \\
$11: 45$ & 1.11 & 1.08 & 0.99 \\
$12: 00$ & 1.12 & 1.02 & 1 \\
$12: 15$ & 1.08 & 0.91 & 0.96 \\
$12: 30$ & 1.085 & 0.910 & 0.92 \\
$12: 45$ & 1.02 & 0.9 & 0.9 \\
$01: 00$ & 1 & 0.890 & 0.88 \\
$01: 15$ & 1.003 & 0.87 & 0.8 \\
$01: 30$ & 0.965 & 0.816 & 0.74 \\
$01: 45$ & 0.942 & 0.760 & 0.65 \\
$02: 00$ & 0.874 & 0.740 & 0.57 \\
$02: 15$ & 0.836 & 0.631 & 0.51 \\
$02: 30$ & 0.766 & 0.602 & 0.463 \\
$02: 45$ & 0.710 & 0.55 & 0.414 \\
$03: 00$ & 0.656 & 0.52 & 0.364 \\
$03: 15$ & 0.554 & 0.449 & 0.293 \\
$03: 30$ & 0.445 & 0.403 & 0.27 \\
$03: 45$ & 0.38 & 0.354 & 0.26 \\
$04: 00$ & 0.36 & 0.308 & 0.24 \\
\hline & & &
\end{tabular}

Table. 4. shows the value of short circuit current of different configuration concerning time.

\subsection{Performance Investigation of a Solar PV Module under Rectangular Shape Transparent Sheet}

However, the solar panel performance with RSTS configuration is not better in comparison with the TSTS configuration. But this configuration is quite better than the normal panel. The efficiency and the output of RSTS configuration are high from the normal panel shown in figure 2, figure 3 and figure 4.

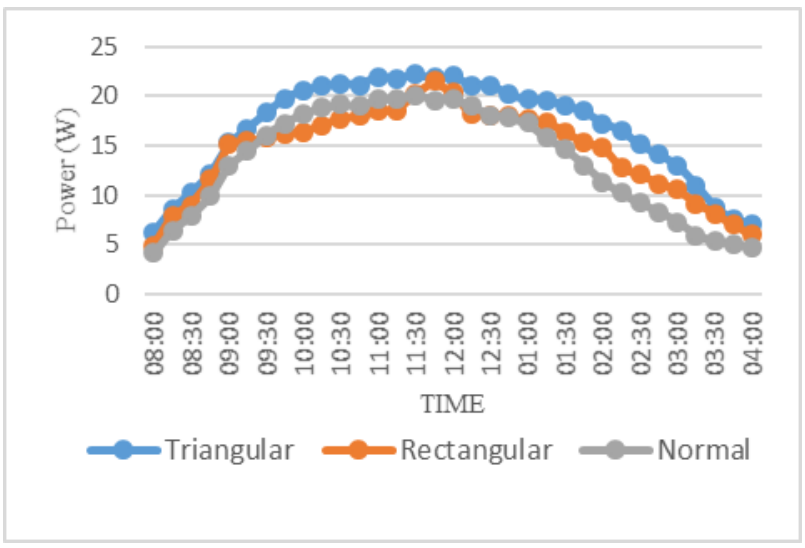

Figure 2. Generated power 
Ankur Kumar Gupta ${ }^{\mathrm{a}^{*}}$, Shushma Kakkar ${ }^{\mathrm{b}}$, Rachna Chaudhary ${ }^{\mathrm{c}}$, Pankaj Kumar Gupta ${ }^{\mathrm{d}}$, Rupendra Kumar Pachauri ${ }^{\mathrm{e}}$

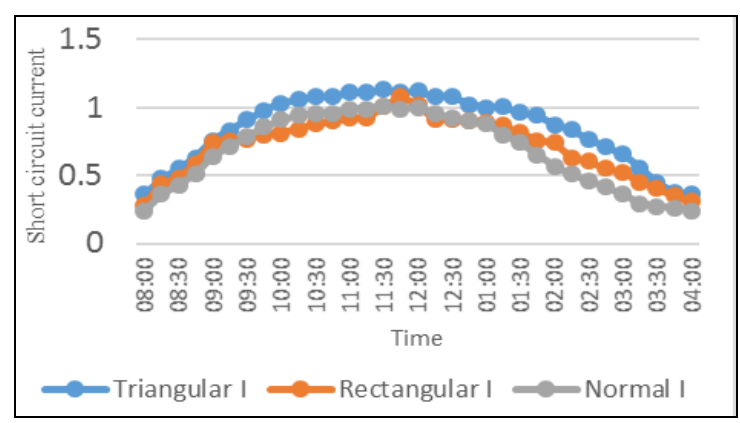

Figure 3. Generated open circuit current

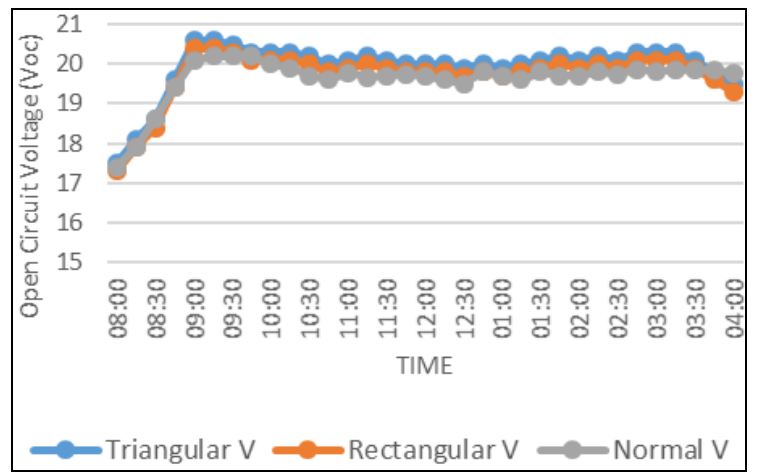

Figure 4. Generated open circuit voltage

Table 5. Irradiance w.r.t Time

\begin{tabular}{ll}
\hline Time & Irradiation \\
\hline 08:00 & $\mathbf{4 1 0}$ \\
$08: 15$ & 440 \\
$08: 30$ & 510 \\
$08: 45$ & 640 \\
$09: 00$ & 722 \\
$09: 15$ & 783 \\
$09: 30$ & 796 \\
$09: 45$ & 826 \\
$10: 00$ & 865 \\
$10: 15$ & 870 \\
$10: 30$ & 889 \\
$10: 45$ & 920 \\
$11: 00$ & 928 \\
$11: 15$ & 942 \\
$11: 30$ & 977 \\
$11: 45$ & 998 \\
$12: 00$ & 1012 \\
$12: 15$ & 1025 \\
$12: 30$ & 1045 \\
$12: 45$ & 1023 \\
$01: 00$ & 1016 \\
$01: 15$ & 1018 \\
$01: 30$ & 965 \\
$01: 45$ & 950 \\
$02: 00$ & 890 \\
$02: 15$ & 886 \\
$02: 30$ & 844 \\
$02: 45$ & 755 \\
$03: 00$ & 704 \\
$03: 15$ & 665 \\
$03: 30$ & 638 \\
$03: 45$ & 618 \\
&
\end{tabular}


Sun Irradiance Trappers for Solar PV Module to Operate On Maximum Power: An Experimental Study

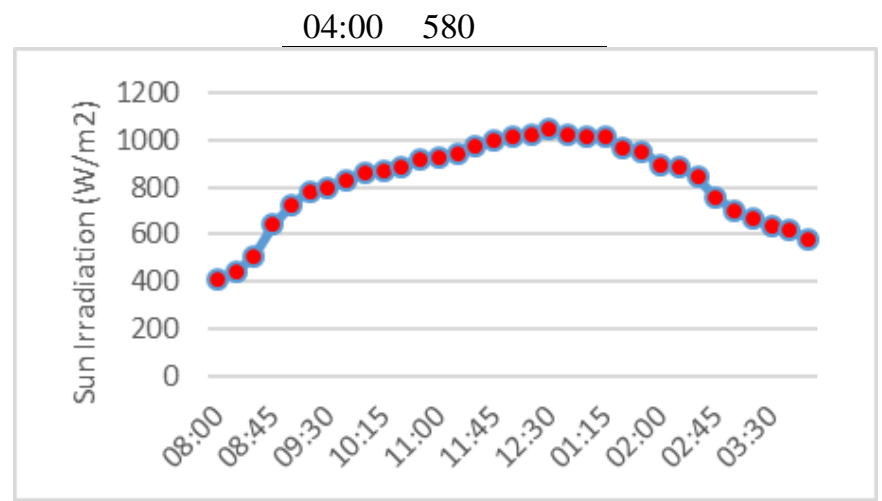

Figure 5. Measurement of sun irradiation $\left(\mathrm{W} / \mathrm{m}^{2}\right)$ during the study

Figure 5 shows the value of associated irradiance under which the test has been performed. This irradiance has been the same for all the panel during testing. The values of irradiance concerning time are shown in Table. 5 .

Table 6. Temperature w.r.t Time

\begin{tabular}{ll}
\hline Time & Temp \\
\hline $08: 00$ & 24 \\
$08: 15$ & 26 \\
$08: 30$ & 28 \\
$08: 45$ & 29 \\
$09: 00$ & 32 \\
$09: 15$ & 35 \\
$09: 30$ & 37 \\
$09: 45$ & 39 \\
$10: 00$ & 40 \\
$10: 15$ & 40 \\
$10: 30$ & 40 \\
$10: 45$ & 41 \\
$11: 00$ & 41 \\
$11: 15$ & 41 \\
$11: 30$ & 40.5 \\
$11: 45$ & 40 \\
$12: 00$ & 41 \\
$12: 15$ & 42 \\
$12: 30$ & 41 \\
$12: 45$ & 40 \\
$01: 00$ & 40 \\
$01: 15$ & 41 \\
$01: 30$ & 40 \\
$01: 45$ & 41 \\
$02: 00$ & 40 \\
$02: 15$ & 39 \\
$02: 30$ & 39 \\
$02: 45$ & 38 \\
$03: 00$ & 38 \\
$03: 15$ & 38 \\
$03: 30$ & 38 \\
$03: 45$ & 37 \\
$04: 00$ & 34 \\
\hline &
\end{tabular}




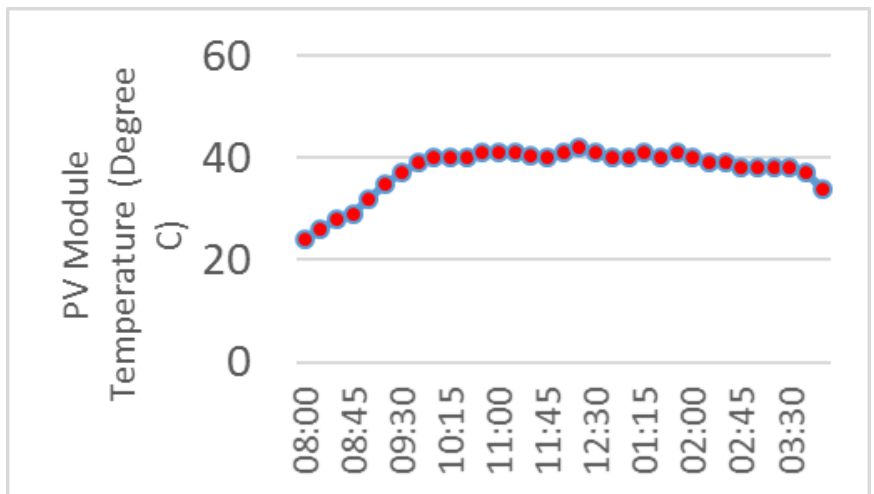

Figure 6. Measurement of module temperature $\left({ }^{\circ} \mathrm{C}\right)$ during the study

The temperature during the test is shown in figure 6. This instantaneous temperature is the same for all the panels during the complete test. However, these techniques have some limitations, such as the cleaning of solar panels, which may be difficult if we placed them on the solar panel. The values of temperature concerning time are shown in Table 6.

\section{Conclusion}

During the experimental study is following salient points are observed as,

- The performance of solar panel with TSTS configuration is found better in comparison of simple plane glass used for the solar panel.

- The performance has been compared to the same panel with different shape of sheet mounted on them.

- The overall performance of the triangular-shaped transparent sheet found better in comparison with other configuration.

- The TSTS configuration provides 22.064 Watt power at 12 am, whereas RSTS configuration provides $20.4 \mathrm{~W}$ simultaneously.

- The TSTS configuration provides 1.12 Amp short circuit current at $12 \mathrm{am}$, whereas RSTS configuration provides 1.02 Amp short circuit current at the same time. The TSTS configuration provides 8.92 percent better value.

- The TSTS configuration provides 20-volt open-circuit voltage at 12 am, whereas RSTS configuration provides 19.8 Volt open-circuit voltage at the same time. The TSTS configuration provides 1 percent better value.

\section{References}

1. Gupta, A.K., Chauhan, Y.K., \& Maity, T. (2018). Experimental investigations and comparison of various MPPT techniques for photovoltaic system. Sādhanā, 43(8), 1-15.

2. Kumar, A., Pachauri, R.K., \& Chauhan, Y.K. (2015). Analysis and performance improvement of solar PV system by solar irradiation tracking. In 2015 International Conference on Energy Economics and Environment (ICEEE), 1-6.

3. Beck, M.E., Wiedeman, S., Huntington, R., VanAlsburg, J., Kanto, E., Butcher, R., \& Britt, J.S. (2005). Advancements in flexible CIGS module manufacturing. In Conference Record of the Thirty-first IEEE Photovoltaic Specialists Conference, 211-214.

4. Farahat, M.A. (2004). Improvement the thermal electric performance of a photovoltaic cells by cooling and concentration techniques. In 39th International Universities Power Engineering Conference, UPEC 2004, 2, 623-628. IEEE.

5. Bonnet-Eymard, M., Boccard, M., Bugnon, G., Meillaud, F., Despeisse, M., Haug, F.J., \& Ballif, C. (2013). Current matching optimization in high-efficiency thin-film silicon tandem solar cells. In 2013 IEEE 39th Photovoltaic Specialists Conference (PVSC), 0184-0187.

6. Arshad, R., Tariq, S., Niaz, M.U., \& Jamil, M. (2014). Improvement in solar panel efficiency using solar concentration by simple mirrors and by cooling. In 2014 International Conference on Robotics and Emerging Allied Technologies in Engineering (iCREATE), 292-295.

7. Huang, B.J., \& Sun, F.S. (2007). Feasibility study of one axis three positions tracking solar PV with low concentration ratio reflector. Energy conversion and management, 48(4), 1273-1280.

8. Ajayi, A.B., Majekodunmi, O.A., \& Shittu, A.S. (2013). Comparison of power output from solar PV panels with reflectors and solar tracker. Journal of Energy technologies and Policy, 3(7), 70-77. 
9. Ahmed, Z., Kazem, H.A., \& Sopian, K. (2013). Effect of dust on photovoltaic performance: Review and research status. Latest Trends in Renewable Energy and Environmental Informatics, 34(6)193-199.

10. Palaskar, V.N., \& Deshmukh, S.P. (2013). A critical review on enhancement in system performance of flat plate hybrid PV/T solar collector system. International Journal of Energy Science, 3(6), 395-402.

11. Anand, V.P., Khan, M.M., Ameen, E., Amuthan, V., \& Pesala, B. (2014). Performance improvement of solar module system using flat plate reflectors. In 2014 International Conference on Advances in Electrical Engineering (ICAEE), 1-4.

12. Kabeel, A., Abdelgaied, M., \& Sathyamurthy, R. (2019). A comprehensive investigation of the optimization cooling technique for improving the performance of the PV module with reflectors under Egyptian conditions. Solar Energy, 186, 257-263.

13. Gupta, A.K., Chauhan, Y.K., Maity, T., \& Nanda, R. (2020). Study of Solar PV Panel under Partial Vacuum Conditions: A Step towards Performance Improvement. IETE Journal of Research, 1-8.

14. Arhun, S., Hnatov, A., Mygal, V., Khodyriev, S., Popova, A., \& Hnatova, H. (2020). An Integrated System of Alternative Sources of Electricity Generation for Charging Urban Electric Buses. In 2020 IEEE 40th International Conference on Electronics and Nanotechnology (ELNANO), 619-624.

15. Gnatov, A., Argun, S., \& Rudenko, N. (2017). Smart road as a complex system of electric power generation. In 2017 IEEE First Ukraine Conference on Electrical and Computer Engineering (UKRCON), 457-461.

16. Paulus, A., Arhun, S., Hnatov, A., Dziubenko, O., \& Ponikarovska, S. (2018). Determination of the best load parameters for productive operation of PV panels of series FS-100M and FS-110P for sustainable energy efficient road pavement. In 2018 IEEE 59th International Scientific Conference on Power and Electrical Engineering of Riga Technical University (RTUCON), 1-6.

17. Gupta, A.K., Chauhan, Y.K., \& Maity, T. (2018). Experimental investigations and comparison of various MPPT techniques for photovoltaic system. Sädhanā, 43(8), 1-15.

18. Datta, D., Mishra, S., \& Rajest, S.S. (2020). Quantification of tolerance limits of engineering system using uncertainty modeling for sustainable energy. International Journal of Intelligent Networks, 1, 1-8. https://doi.org/10.1016/j.ijin.2020.05.006 